\section{New ways of looking at cities}

\section{Michael Batty}

IN the past ten years, there has been a sea change in the way geographers and planners have begun to think about the growth and form of cities. Top-down approaches based on models that attempt to simulate the entire organization of the city in analogy to classical gravitation are being supplanted by theories emphasizing the way in which uncoordinated local decision-making gives rise to coordinated global patterns which define the size and shape of cities in familiar ways. Cities appear to be yet further examples of self-organizing structures that emerge from local actions ${ }^{1}$. Examples have been demonstrated using models based on diffusion-limited aggregation, in which fractal clusters reminiscent of cities with very dominant central business districts can be grown using local rules from a single seed marking the origin of development ${ }^{2}$.

In their paper on page 608 of this issue $^{3}$, Makse, Havlin and Stanley provide one of the clearest examples yet of such an approach. Their analysis generates forms consistent with power laws describing how population in real cities varies with radius and area, and with relations governing their size and spacing.

\section{Patterns}

Cities of course are not single clusters of development centred around their central business districts. They are considerably more complex than this, for even the simplest patterns grow from the amalgamation of clusters formed from small villages, and the world's largest metropolitan regions are composed of many interdependent towns of varying sizes. Models are required that show how such interconnected systems emerge. In moving the model from diffusionlimited aggregation to percolation, and in adding local correlations to achieve freestanding growth of small clusters, Makse and co-workers show how systems of cities with properties that are consistent with empirical observation in large city regions - they use London and Berlin as examples - can evolve. Although this model is somewhat less parsimonious than diffusion-limited aggregation, in that local correlations have to be assumed to generate global correlations, it clearly generates greater realism.

The importance of this general approach to a theory of cities is in its ability to link form to function. Much urban theory developed during the past 50 years has been unable to link the underlying economic and ecological theory of cities to the actual spatial patterns which we observe. The model with diffusion-limited aggregation shows how widely observed scaling relations such as population density profiles can be linked to simple processes of local growth that give rise to city-like structures. Makse and colleagues' model goes further. It shows how the relations that relate the rank and area of cities to their size, and which are generated by central place theory (the cornerstone of human geography that explains how economic dependence within the hierarchy of cities translates into their location), are entirely consistent with urban form across many scales, from the smallest cluster to the largest urban region. They also show how other types of

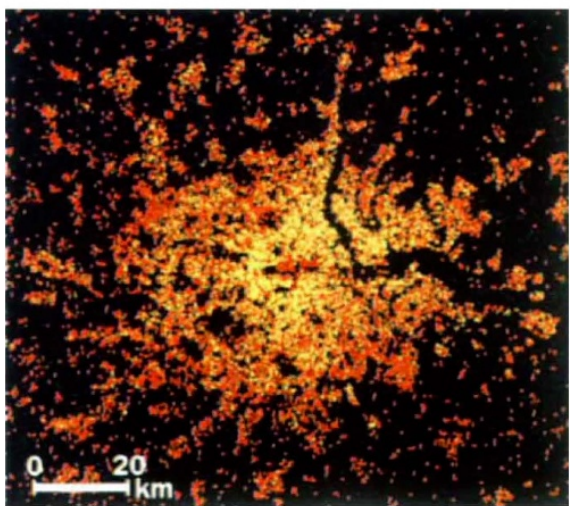

Although it is possible to see the morphology of population density in London ${ }^{10}$ as a single cluster focused on the central business district, a better explanation of this pattern is as a hierarchy of clusters of different sizes.

scaling, such as the perimeter-scale relation for connected clusters, which is consistent with the notion of a fractal boundary ${ }^{2,4}$, can be generated. Their work is related to developments in regional trade theory due to Krugman ${ }^{5}$ and to Bak's weak chaos theory ${ }^{6}$, both of which are based on the principle of self-organization which gives this new theory of cities its most informed economic rationale to date. A synthesis is in the offing, and it looks as though the time is now ripe for the new approach to cities and urban form for which we have been waiting for more than a generation.

The implications of the simulations made by Makse et al. are wider than the development of new theory per se. The principle that underpins their approach is central to the transformation from industrial to post-industrial cities and the ways they might be planned. Cities of the early industrial era were initially single clusters, monocentric forms organized around the central business district. Much of the basic theory that was fashioned in their explanation took this evident simplification, based on the notion that all significant travel within the city was from homes in the periphery to work in the core, as their starting point ${ }^{7}$.

But as economic constraints on communication have loosened and new technologies emerged, the journey to work is no longer the dominant activity in the city, and cities based on a single core are disappearing. The phenomena of the 'edge city' in North America, and the world city with its global tentacles of communication, are evidence enough that this old vision of the city is passing. Work within the new scheme, based on modelling employing diffusion-limited aggregation, for example ${ }^{2}$, has so far retained the monocentric assumption. But Makse et al. break with this, perhaps because they have none of the intellectual baggage which those closer to the field carry evidence once again that fresh insights in science come from outsiders using established approaches in new fields.

\section{Planning}

Most important, in my view, is the impact this change in our understanding of cities may have on planning and intervention. Urban planning, which was institutionalized in western societies over 100 years ago, remains a top-down activity. This view is waning as societies become decentralized, and as central planning based on command economies collapses? Understanding complex systems must be from the ground up as more realistic ways of managing complexity are fashioned. Makse et al. suggest, quite rightly, that central planning based on instruments such as the Green Belt policies that have been used to contain London seems to have had little effect on the shape of the metropolis, and that this is consistent with the ways cities are formed from more local actions without any centralized intelligence.

Theories like these are generating changes in our views of cities and how we might alleviate their problems. They are likely to be much more effective than those that have operated hitherto.

Michael Batty is in the Centre for Advanced Spatial Analysis, University College London, Gower Street, London WC1E 6BT, UK.

1. Allen, P. M. Proc. natn. Acad. Sci. U.S.A. 73, 665 (1976).

2. Batty, M. \& Longley, P. Fractal Cities: A Geometry of Form and Function (Academic, San Diego, 1994).

. Makse, H. A., Havlin, S. \& Stanley, H. E. Nature 377 608-612 (1995).

4. Frankhauser, P. La Fractalité Des Structures Urbaines (Collection Villes, Anthropos, Paris, 1994).

5. Krugman, P. Am. Econ. Assoc., Pap. Proc. 84, 412-416 (1994).

6. Bak, P., Tang, C. \& Wiesenfeld, K. Phys. Rev. A38, 364-374 (1988).

7. Henderson, J. V. Economic Theory and the Cities (Academic, San Diego, 1985).

8. Garreau, J Edge City: Life on the New Frontier (Doubleday, New York, 1991)

9. Kelly, K. Out of Control: The New Biology of Machines (Fourth Estate, London, 1994).

10. Martin, D. Trans. Inst. Br. Geogr. (NS) 14, 90-97 (1989). 